\title{
The Development and Application of a Computerized Intormation-Processing Test Battery
}

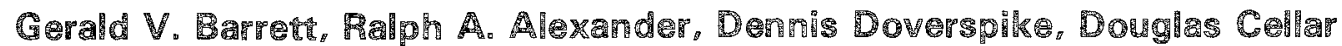 \\ The University of Akron
}

Jay C. Thomas

Rico Universidy

To bridge the gap between computerized testing and information-processing-based measurement, a battery of computerized information-processingbased ability and preference measures was developed. The information-processing and preference measures and a battery of paper-and-pencil tests were administered to 64 college students. Although the internal-consistency reliabilities of the computerized information-processing measures were adequate, test-retest reliabilities were lower than desirable for ability measures. The computerized information-processing measures possessed moderate convergent validity but had low correlations with traditional paper-and-pencil measures. Of the computerized preference measures, the most promising results were obtained with the Stimulus Pace measure. A major problem with the use of the computerized information-processing measures in applied settings would be administration time, as the battery took approximately 4 hours. In addition, problems with the stability of results over time and substantial practice effects suggest that even longer testing sessions would be required to obtain reliable measures. Although information-processing measures of short-term memory have, at best, low correlations with traditional intelligence tests, their ability to predict real-world tasks has yet to be sufficiently researched.

Two recent promising trends in the area of aptitude measurement are computerized testing and information-processing-based measure-

APPLIED PSYCHOLOGICAL MEASUREMENT Vol. 6. No. 1, Winter 1982, pp. 13-29

(c) Copyright 1982 Applied Psychological Measurement Inc. 0146-6216/82/010013-17\$1.85 ment. Advantages of computer controlled test administration and scoring include its adaptive potential (Lord, 1980; Wood, 1974), ease of administration and scoring, and increased similarity of stimulus characteristics and formats to those found in applied settings (Cory, 1977; Cory, Rimland, \& Bryson, 1977). The advantages of the differential information-processingbased approach include the potential for understanding human ability tests in terms of the cognitive processes contributing to individual differences (Sternberg, R., 1979; Whitely, 1977). This report summarizes an attempt to develop (1) a battery of computerized information-processing-based ability measures that could be group administered for possible use in applied settings and (2) computerized measures of preferences for various task dimensions.

The term "information-processing" has been used to refer to a wide range of perspectives and research techniques in both social and cognitive psychology (Stemberg, R., 1977). In general, the information-processing approach has viewed the human mind as an information processor that codes, stores, and retrieves environmental inputs (Neisser, 1967; Newell \& Simon, 1972). Historically, information-processing measures have moved from experimental studies, which ignored the role of individual differences, to more recent attempts to measure individual differences in information-processing abilities (Car. 
roll, 1976). A variety of tests of information-processing ability have been developed, including group-administered paper-and-pencil tests, such as the Kit of Factor $\mathbb{R}$ eferenced Tests (Ekstrom, French, Harman, \& Dermen, 1976); apparatus tests, including the Rod-and-Frame Test (Within, Lewis, Machover, Meissner, \& Wagner, 1954) and tests of auditory and visual selective attention (Avolio, Alexander, Barrett, \& Sterns, 1981; Mihal \& Barrett, 1976); and tests of short-term memory (Hunt, Frost, \& Lunneborg, 1973).

A major area of information-processing research has consisted of attempts to relate shortterm or immediate memory to human intelligence (Snow, 1979). Hunt and associates (Hunt, 1980; Hunt et al., 1973; Hunt, Lunneborg, \& Lewis, 1975; Lunneborg, 1977, 1978) have conducted a number of studies of the relationship between individual differences in information processing and paper-and-pencil intelligence tests. These studies have indicated that there is substantial individual variation in performance on experimentally derived measures of information processing that is related to scores on intelligence tests. More specifically, in normal subjects there has been some evidence of correlations between speed of coding and search in short-term memory and intelligence, but the correlations have not been large. However, large differences have appeared when comparing extreme groups, i.e., retardates and high-school students (Hunt, 1980).

In a series of related studies of choice reaction time (RT), Lunneborg (1977) found different patterns of relationships between choice $R T$ and paper-and-pencil test performance, depending on the subject population used and the techrique used to measure choice $\mathbb{R T}$. Lumneborg did not report reliability data but did mention the necessity of collecting reliable assessments. Lunneborg found that for high-school students approwimately 300 trials were needed for choice $\mathbb{R T}$ to stabilize. However, neither the data from early RT trials nor later RT trials showed consistent results over subjects or RT measures.
For their investigation of individual differences in information processing, Chiang and Atkinson (1976) selected a few well-researched information-processing measures of short-term memory and visual processing based on the memory-scanning paradigm of $\mathbb{S}$. Sternberg $(1966,1969,1975)$. They attempted to obtain highly reliable data and to investigate the interrelationships among information-processing skills. Conditions were set to maximize the probability of high reliability (1) by allowing a whole session for practice trials, (2) by counter. balancing and randomizing tasks, and (3) by giving subjects control over intertrial interval and cumulative feedback on performance. The tasks they selected were a memory search task, a visual search task, and a digit span task. For the memory search task and the visual search task, both slope and intercept were calculated. Splithalf rellability for all parameters was greater than .89 . Test-retest reliability was .70 or higher except for memory search slope and visual search slope, which for Day 1 vs. Day 2 was .28 and 29 , respectively. Correlations between measures indicated that the two intercept measures were highly correlated $(=.97)$, as were the slope measures $(r=.83)$. Thus, Chiang and Atkinson's (1976) resullts showed that informationprocessing-based measures could produce reliable individual differences that were related to other important criteria. Although the results were suggestive of important relationships, generalizability could be questioned in that the sample sizes were small and the sample was restricted toward the upper levels of intelligence: Mean SAT verbal score was 613 and mean SAT quantitative score was 660 .

The present program of research focused on the development of computerized information. processing measures based on the memory-scanning paradigm of $\mathbf{S}$. Sternberg (1966, 1969, 1975), as employed by Chiang and Atkinson (1976). In this paradigm, the time required to compare an immediate stimulus to a stimulus set in short-term memory consists of encoding, binary decision, and response production. As 
stimuli are added to the memory set, it is possible by regressing $\mathbb{R T}$ on memory set size to arrive at a slope measure that is interpreted as an index of speed of scanning (Taylor, 1976). Reliability and validity were studied in a more realistic testing setting (1) by reducing practice sessions, (2) by presenting whole tasks, and (3) by presenting the tasks to a group rather than an individual, thereby eliminating individual controll over intertrial interval.

As in information-processing research, in the area of job satisfaction and job design the role of individual differences in preferences has been minimized in the work of early researchers such as Taylor, Herzberg, and Maslow (Barret, Dambrot, \& Smith, 1977). More recently, work has shifted to the investigation of individual differences in preferences for job dimensions as exemplified by Tumer and Lawrence (1965), Blood and Hulin (1967), Hackman and Lawler (1971), and the congruence approaches of Erench and Kahn (1962), and Barret (1978). Individual differences in preferences for job dimensions have been traditionally measured by paper-and-pencill tests such as the Job Diagnostic Survey (Hackman \& Oldham, 1975) and the Work Itself/Work Environment Preference Questionnaire (Cascio, 1973) and have been found to be related to ability and personality measures (Barrett et al., 1977). More recently, a computerized information-processing-based approach to measuring preferences has been developed and found to correlate with information-processing abilities (Avolio, Alexander, Barrett, \& Stems, 1979; Panek, Barrett, Alexander, \& Sterns, 1979). This procedure suffered from the limitation of requiring individual administration. The present study describes an attempt to develop group administered, computerized measures of preferences for job dimensions.

\section{Method}

\section{Sulbiects}

Subjects consisted of 64 college student volunteers from an urban midwestem university
(38 female, 26 male) who were paid $\$ 2.50$ per hour for participation in a psychology experiment. The mean age of the subjects was 21 . The mean Wesman Personnel Classification Test totall score was 34.7 , which corresponded to a percentile score of 21 for the norm group of college sophomores enrolled at a midwestern university (Wesman, 1965).

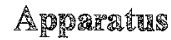

Stimuli were presented over six $25.5 \times 38.5 \mathrm{~cm}$ RCA color television monitors (Model JU 970W) situated in adjacent individual viewing booths. Luminance level was controlled in the booths by subjectively adjusting a theostatically controlled light to match the intensity of light emanating from the television screen. The booths were painted flat black and subjects wore headphones through which a low intensity level of white noise was generated to limit possible distractions.

The monitors were interfaced with a PDP $11 / 10$ minicomputer through which graphic displays were transmitted and subject responses were collected and stored for subsequent analysis. The transmission of tasks and data collection were controlled through a Tektroniz 4010 CRT and Princeton Electronics Products PEP 500 Unit which linked the minicomputer with the television monitors and response panels.

The response panels were metal boxes with an array of two cm square buttons. For each task a labeled template was placed over the array of buttons exposing only those buttons represent. ing the appropriate response options for that task. Subjects were instructed to place their index fingers on these keys so as to eliminate additional response time due to key search.

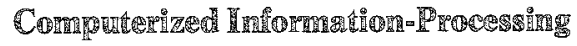

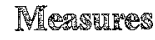

A battery of information-processing tasks was developed. The first three tasks were modeled after the memory-scanning task developed by $\mathbf{S}$. Stermberg $(1966,1969)$ and employed in the 
Chiang and Atkinson (1976) study. The tasks developed were Choice $R T$, a sequential memoryscanning task (Sequential Memory), a simultaneous memory-scanning task (Simultaneous Memory), and a visual-scanning task (Visual Search). In addition, a number of response accuracy tasks were developed. These were Multiple Item Access, Linear Scanning, Matrix Scanning, Array Memory, and Vector Memory.

Choice Reaction Time. This task consisted of the presentation of a warning signal (an asterisk) followed 1 to 5 sec later, the interval determined randomly, by the presentation of a letter or a number. The subject responded by pressing the appropriate button on the response panel according to whether a letter or a number had been presented. There were a total of 30 trials. The score consisted of mean response time in msec, with only correct responses being included.

Sequential Memory. This task consisted of from one to five $2.22 \mathrm{~cm}$ letters presented sequentially; each letter was presented for 800 msec followed by a $200 \mathrm{msec}$ delay. Following the presentation of the last letter, there was a 2 sec delay, then the probe letter was presented. The subject responded by pressing the appropriate button on the response panel, reflecting whether the probe letter was the same or different from any one of the memory set letters. Subjects had $3 \mathrm{sec}$ to respond. There were a total of 60 trials. Measures of slope, intercept, and number correct were computed. To calculate slope and intercept, response time in msec was regressed on number of letters in the memory set. Only correct trials were used to compute slope and intercept.

Simultaneous Memory. This task consisted of from one to five $2.22 \mathrm{~cm}$ letters presented simultaneously in a horizontal array for $3 \mathrm{sec}$. These letters were erased and after a 2-sec delay the probe letter was presented. The subject responded by pressing the appropriate button on the response panel, reflecting whether the probe letter was the same or different from any one of the memory set letters. Subjects had 3 sec to respond. There were a total of 60 trials. Measures of slope, intercept, and number correct were computed. Only correct trials were included in the computation of slope and intercept.

Visual Search. This task consisted of the presentation of a $2.22 \mathrm{~cm}$ probe letter for 800 msec before it was erased. After a delay of $2 \mathrm{sec}$, a set of from one to five $2.22 \mathrm{~cm}$ letters was presented simultaneously in a horizontal array for 3 sec, then erased. The subject responded by pressing the appropriate button on the response panel, reflecting whether the probe letter was the same or different from any one of the memory set letters. Subjects had $3 \mathrm{sec}$ to respond. There were a total of 60 trials. Measures of slope, intercept, and number correct were computed. Only correct trials were included in the computation of slope and intercept.

Multiple Item Access. This task consisted of the presentation of two sets of five $2.22 \mathrm{~cm}$ letters. The first set of letters was presented simultaneously in a horizontal array for $3 \mathrm{sec}$, then erased. After a delay of $2 \mathrm{sec}$, a second set of five letters were presented simultaneously in a horizontal array for $3 \mathrm{sec}$. Subjects then responded according to how many letters, one to five, were the same in the sets of letters. There were a total of 60 trials. The score was number correct.

Linear Scanning. Twenty equilateral triangles $(1.50 \mathrm{~cm}$ on a side) were presented in a row. Each of the triangles had a line through it with the exception of one, two, three, or four of the triangles, which did not have lines through them. The row of triangles was presented for 1.5 sec and subsequently erased, at which time the subject was required to respond as to whether one, two, three, or four of the triangles did not have lines through them by pressing the corresponding button on the response panel. The number of triangles without lines through them varied randomly across the 20 trials. Subjects had $3 \mathrm{sec}$ in which to respond. This measure was scored in terms of the number of correct responses.

Matrix Scanning. This measure differed from the Linear Scanning measure (above) only in that the triangles were presented in a $4 \times 5$ matrix. The display size was $7.0 \mathrm{~cm} \times 7.5 \mathrm{~cm}$. 
Array Memory. In this task four $2.22 \mathrm{~cm}$ figures were presented simultaneously on the screen for 2 sec and them were subsequently erased. The figures consisted of a pound sign, arrow, roman numeral five, and an "X." The subject was then presented with one of the four figures and was required to indicate on the response panel in what area of the screen that figure had previously appeared. The response options were upper left, upper center, upper right, lower left, lower center, and lower right. Subjects had $3 \mathrm{sec}$ in which to respond. There were a total of 18 trials. This measure was scored in terms of the number of correct responses.

Vector Memory. This task was identical to the above task with the exception that after presentation of the four figures, the subject was presented with two figures and required to respond in which area of the screen the two figures would meet if one of them moved horizontally and the other moved vertically. The subjects were told which two figures to respond to but not which direction either of them would move. They were also told that the target figures could not move over another figure; due to the positioning of the figures, there was only one possible correct response. Subjects had $3 \mathrm{sec}$ in which to respond. There were a total of 18 trials. This measure was scored in terms of the number of correct responses.

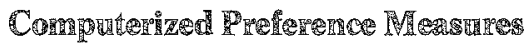

Stimulus Pace. Subjects were presented with a long, thin horizontal rectangle which was 2.54 $\mathrm{cm} \times 35 \mathrm{~cm}$. A series of 11 squares then filled the rectangle from left to right sequentially at one of nine rates. Thus, the length of time required to fill the rectangle varied on each trial. The nine speeds, in terms of time to complete the rectangle in msec, were $2,500,5,000,6,000,7,000$, $7,500,8,000,9,000,10,000$, and 11,000. Each speed was presented eight times for a total of 72 trials. The subject was instructed to indicate whether the length of time to fill the rectangle was "shorter than" or "longer tham" the length of time preferted for the presentation of stimuli on a job. Responses were indicated by pressing the appropriate batton on a response panel on each trial. The score, or preference for pace, was the speed at which the subject responded "shorter than" $50 \%$ of the time. When this value fell between two speeds, it was computed using an algorithm for a graphical interpolation.

Stimulus Variety. The measure of preference for stimulus variety consisted of the presentation of a grid with two rows and three columns. The subjects were told that six different symbols represented the greatest amount of stimulus variety possible on a job and the same symbol in all the grids represented the least amount of stimulus variety possible on the job. The subjects were presented with each of the possible number of symbols eight times. Thus, there were 48 trials. The subjects were instructed to indicate whether the amount of stimulus variety present in the grid was "less than" or "greater than" the amount they would prefer on a job. Responses were indicated by pushing the appropriate button on a response panel for each trial. The score, or preference for stimulus variety, was the value at which the subject responded "less than" $50 \%$ of the time. When this value fell between two levels of stimulus variety, it was computed using an algorithn for a graphical interpolation.

Response Variety. The measure of preference for response variety consisted of a grid with three rows and two columns. The subjects were told that six different symbols represented the greatest amount of response variety; and the same symbol in all the grids, the least amount of response variety. The subjects were presented with each of the possible number of symbols eight times. Thus, there were 48 trials. The subjects were instructed to indicate whether the amount of response variety presented in the grid was "less than" or "greater than" the amount they would prefer on the job. Responses were indicated by pressing the appropriate button on the response panel. The score, or preference for response variety, was the value at which the subject responded "less than" $50 \%$ of the time. When this value fell between two levels of re- 
sponse variety, it was computed using an algorithm for a graphical interpolation.

\section{Other IMearerises}

The paper-and-pencil battery consisted of the following: the Wesman Personnel Classinication Test (Wesman, 1965); the Group Embedded Eigures Test (Witkin, Olman, Raskin, \& Karp, 1971); the Picture-Number Memory Test and Finding A's Test (Ekstrom et al., 1976); the Mimnesota Paper Form Board (Likert \& Quasha, 1970); and the Auditory Selective Attention Test (ASAT), an individualy administered dichotic listening task (Gopher \& Kahneman, 1971; Mhal \& Barrett, 1976). In addition, a paper-and-pencil personality test, the Maudsley Personality Inventory (K napp, 1962), and a paper-and-pencil preference measure, the Work Itself/Work Environment Preference Questionnaire (Cascio, 1973), were administered.

\section{Proced}

Subjects were tested on 5 dinferent days. The first session consisted of 3 hours during which the paper-and-pencil battery and ASAT were administered. Within a week the subjects ato tended a second session. The second session took 4 hours and consisted of the administration of the information-processing test battery. The battery was administered to six subjects at a time and always in the same temporal order. The order of the battery was as follows: Choice RT, Sequential Memory, Simultaneous Memory, Visual Search, Muliple tem Access, Linear Scanning, Matrix Scanning, Array Menory, and Vector Memory. Each task was preceded by five practice trials for each measure and instructions. Subjects were given two 5-minute breaks. A simple RT task was administered as a warmup and was not scored. The third session met the same week for one hour and consisted of the administration of the computerized preierence measures.

Two weeks to a month later the subjects were brought back for retesting. The fourth session consisted of the second administration of the information-processing measure. Administration was the same as for the first testing. The fifth session was given within a week of the fownth session and consisted of the second administration of the computerized preference measures. Due to scheduling difficulties incurred by trying to find four open hours in a college student's schedule, not all subjects could be retested at the exact same time interval. Furthermore, due to a failure to return by one subject and equipment malunctions, complete retest data was available on only 55 or fewer subjects for the informationprocessing tasks. Retest data for the preferences were obtained for all 64 subjects.

\section{Preser}

Because of the large number of measures derived from the computerized information-processing test battery, the measures are listed by number only in the tables as follows: (1) Sequential Memory Intercept; (2) Sequential Memory Slope; (3) Sequential Memory Correct; (4) Simultaneous Memory Intercept; (5) Simultaneous Memory Slope; (6) Simultaneous Memory Correct; (7) Visual Search Intercept; (8) Visual Search Slope; (9) Visual Search Correct; (10) Multiple Item Access; (11) Linear Scanning; (12) Matrix Scanning; (13) Array Memory; (14) Vector Memory; and (15) Choice RT. Although for use in applied settings, the results from the initial trials would appear to be of greatest interest. results from both the initial and retest trials are presented for the computerized informationprocessing battery.

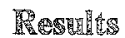

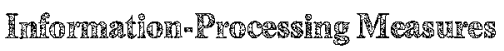

Table 1 contains the means and standard deviations for the 15 information-processing measures. The large standard deviations in task performance support the presence of large individual differences in information-processing task performance. The only significant mean 
Table I

Means and Standard Deviations for the Information-Processing Tasks

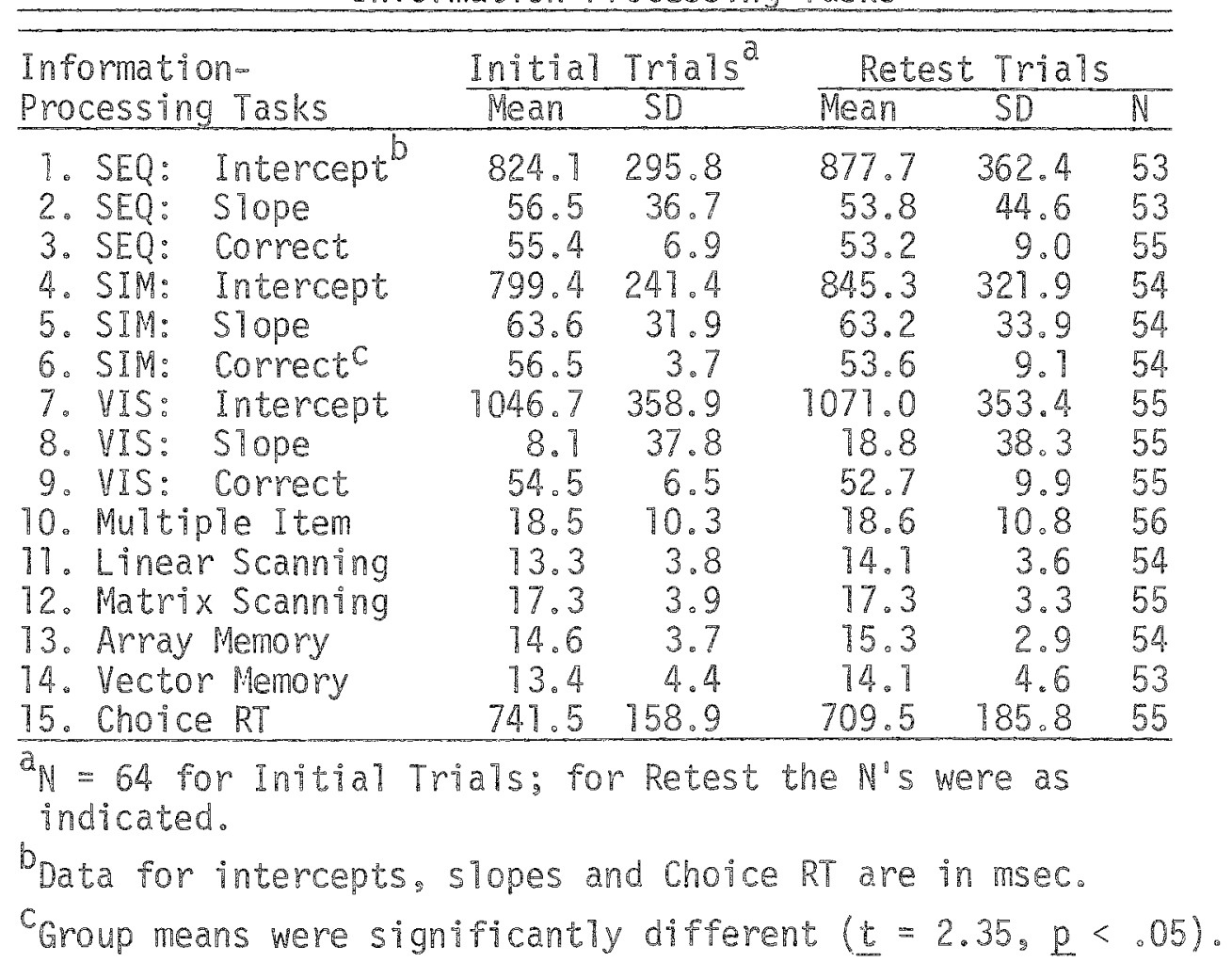

change from initial to retest trials was for Simultaneous Memory Correct. Inspection of Table 1 also reveals that the mean slope for the Visual Search task was much lower than the slope for either the Sequential Memory or the Simultaneous Memory task, and also much lower than the value of $42 \mathrm{msec} / \mathrm{letter}$ for the slope reported by Chiang and Atkinson (1976). This was the result of a large number of subjects, $39 \%$, obtailming negative slopes on the Visual Search task. This result was inconsistent with the results of Chiang and Atkinson (1976), where no regative slopes were reported. Inspection of a plot of the slope values suggested that they were the results of chance riluctuations from a mean slope of zero.

Table 2 contains the rellability data from the information-processing tasks. As a measure of internal consistency, split-hall was chosen due to the necessity of having surficient points to calculate the slope and intercept walues. Thus, calculation of the slope and intercept for the split-half reliabillites was based on 30 trials. Inspection of Table 2 reveals that with the exception of the slope measures, splithalf reliablities were above .80 . For the slope measures, split-hall reliability ranged from $r=.17$ for Viswal Search Slope to $r=.68$ for Simulitaneous Memory Slope. The test-retest rellabilities were based on a 2- to 4-week intertrial interval. Retest reliabillties were generally low, ranging from $p=.80$ for Visual Search Slope to $r=.60$ for Choice RT.

The intercorrelations among the informationprocessing tasks are presented in Table 3. CorreIations for the initial trials are presented above the diagonal; correlations for the retest trials are presented below the diagonal. Inspection of Table 3 provides support for the convergent and 
Table 2

Reliabilities for the Information-Processing Tasks

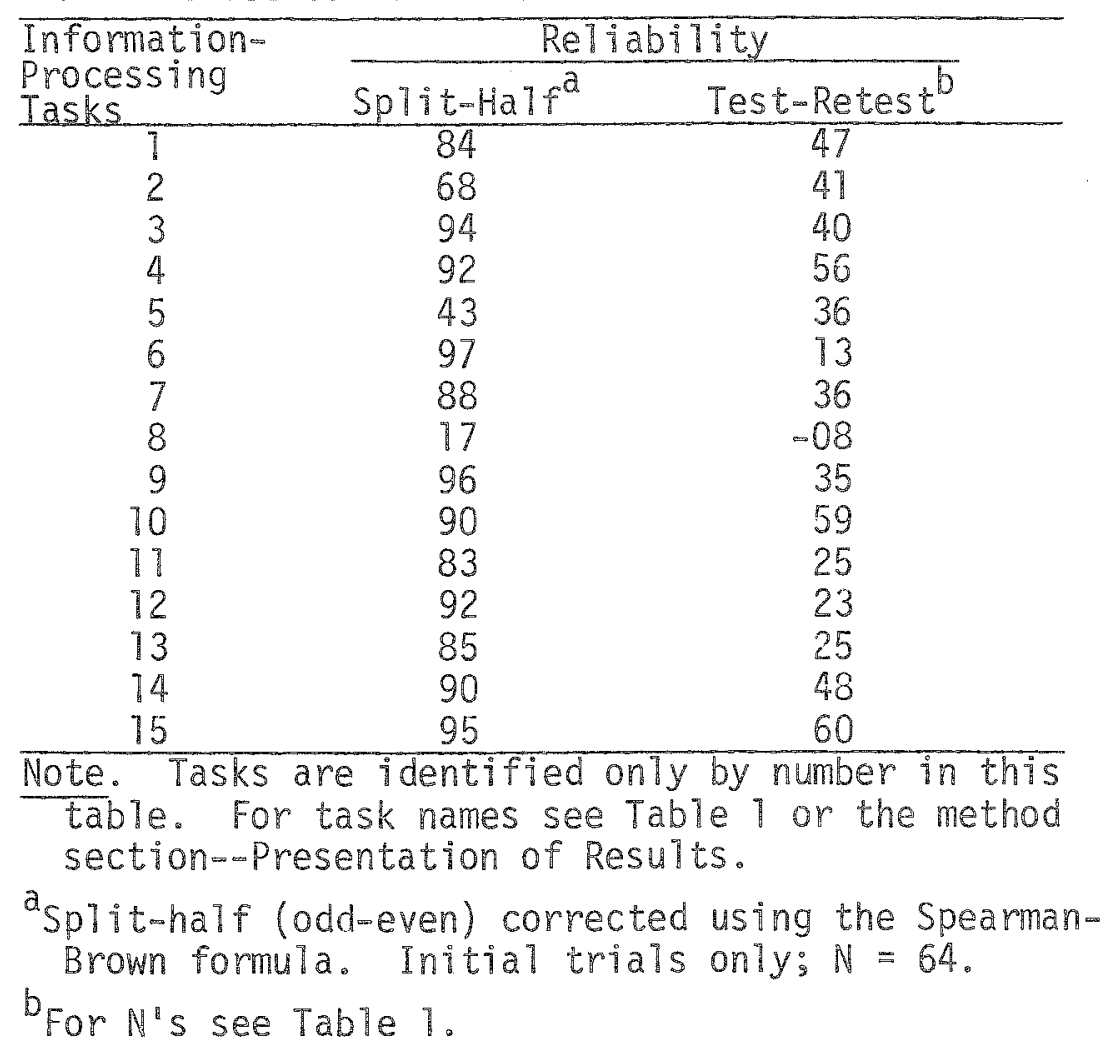

discriminant validity of several of the measures. The correlations between the three intercept measures were all above. 73 and all three intercept measures correlated with Choice $\mathbb{R} T$. For the initial trials there were few significant correlations between the intercept measures and the other measures; and although for the retest trial there were a number of significant correlations between the intercept and other measures, most were in the .3 range and far less than the intercorrelations of the intercept measures. There was less evidence for the convergent validity of the slope measures, although Sequential Memory Slope and Simultaneous Memory Slope were moderately correlated in both initial and retest trials. Sequential Memory Correct, Simultaneous Memory Correct, and Visual Search Correct were also highly correlated for both trials and generally were not significantly correlated or had low to moderate correlations with other measuires.

Linear and Matrix Scanning were highly correllated and had low to moderate correlations with other measures requiring visual scanning, i.e., Visual Search Correct, Array Memory, and Vector Memory. Array Memory and Vector Memory were also significantly correlated and significantly correlated with a number of other accuracy measures. Thus, there was some support for the convergent and divergent validity of the intercept measures, scanning tasks, and Array Memory and Vector Memory tasks. Although Sequential Memory Slope and Visual Search Slope had been found to be highly correlated in past research (Chiang \& Atkinson, 1976), in the present study there was no evidence of convergent validity for the three slope measures. 


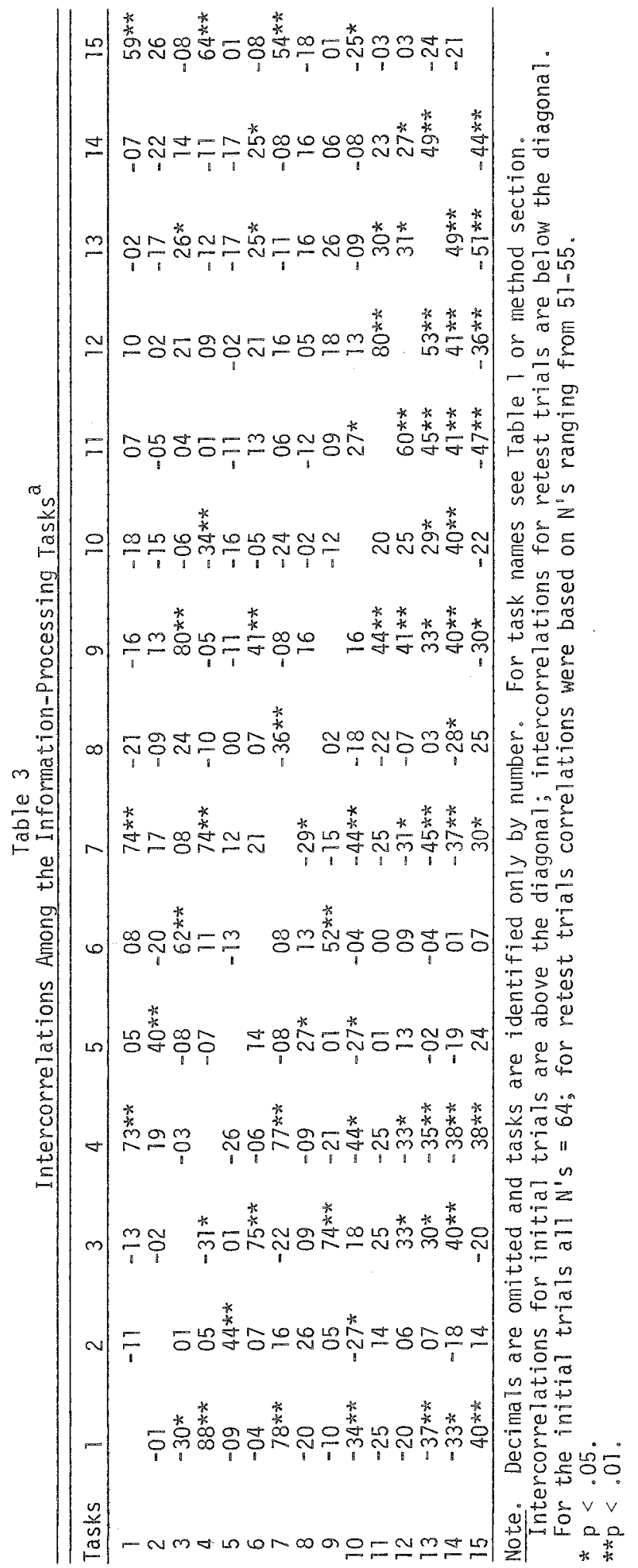


According to the model for the scamning tasks, the intercepts for the scanning tasks should have been equivalent to Choice $\mathbb{R T}$. Therefore, the partial correlations between the intercept measures from the inivial trials, controlling for Choice RT, were calculated. Controlling for Choice RT, the partial correlations between $S$ equential Memory Intercept and Simultaneous Memory Intercept $(r=-.34, p<.01)$, Sequerntial Memory Intercept and Visual Search Intercept $(p=.62, p<.001)$, and Simultaneous Memory Intercept and Visual Search Intercept $(r=.62, p<.001)$ were all significant. Thus, the intercept measures contained a component, not found in Choice RT, on which there were individual differences.

The correlations between scores on the information-processing measures and scores on the battery of traditional paper-and-pencil tests are presented in Table 4. In general, correlations were low or nonsignificant between the information-processing tasks and the paper-and-pencil test battery. Information-processing abillity was not related consistently or strongly to verbal, quantitative, or overall intelligence as measured by the Wesman, with the exception of one of the accuracy measures, Vector Memory, which correlated significantly with the total Wesman score across both trials. Nor did informationprocessing ability correlate strongly or consistently with a measure of associative memory, the Picture Number Test. $\mathbb{A}$ measure of perceptual speed, Finding $A^{\prime} s$, did correlate significantly with speed of memory scanning as measured by Sequential Memory Slope and Simultaneous Memory Slope. The negative correlation indicated that the higher the score on Finding $\mathrm{A}^{\prime}$, and thus the faster the perceptual speed, the lower the slope value, and thus the faster the speed of memory search.

The Minnesota Paper Form Board, which required the manipulation and visualization of objects in space, correlated significantly with Vector Memory, which also required this ability. Vector Memory, Array Memory, and Choice RT correlated significantly across both trials with the Group Embedded Figures Test, a measure of field independence. This indicated that speed of reactions in a simple decision situation and the ability to visualize and manipulate objects in space were both related to field independence. ASAT, a dichotic listening test of selective attention, significantly correlated with a number of information-processing tasks and had consistently moderate correlations with Choice $\mathbb{R T}$. There was only one significant correlation between the information-processing tasks and the Maudsley Personality Inventory. For the retest trial, Choice $\mathbb{R}$ was negatively correlared with the Extroversion scale score.

\section{Prefereren}

The means and standard deviations for the computerized preference measures are presented in Table 5. For Stimulus Pace the minimum value, 227 secs, represented a stimulus being presented every 227 msecs. Thus, the larger the preferred Stimulus Pace value, the slower the speed of preferred presentation. For Stimulus Variety and Response Variety, a larger value indicated a preference for greater variety. Inspection of the preference data revealed that although Stimulus Pace appeared to be normally distributed, Stimulus Variety and Response Variety were negatively skewed.

Test-retest reliabilities are also presented in Table 5. The retest interval ranged from 2 to 4 weeks. Inspection of Table 5 reveals that the test-retest reliabilities were lower than might be desired for stable preference values.

Table 5 also contains data on the intercorrelations of the computerized preference measures. For the computerized preferences only the initial trials are presented here because of space limitations, similarity of results between initial trial and retest, and the assumption that the initial trial results would reflect more adequately the resullts to be obtained in applied settings. The correlation between Stimulus Variety and Response Variety was as high as the rest-retest reliabilities for the two measures. The corre- 


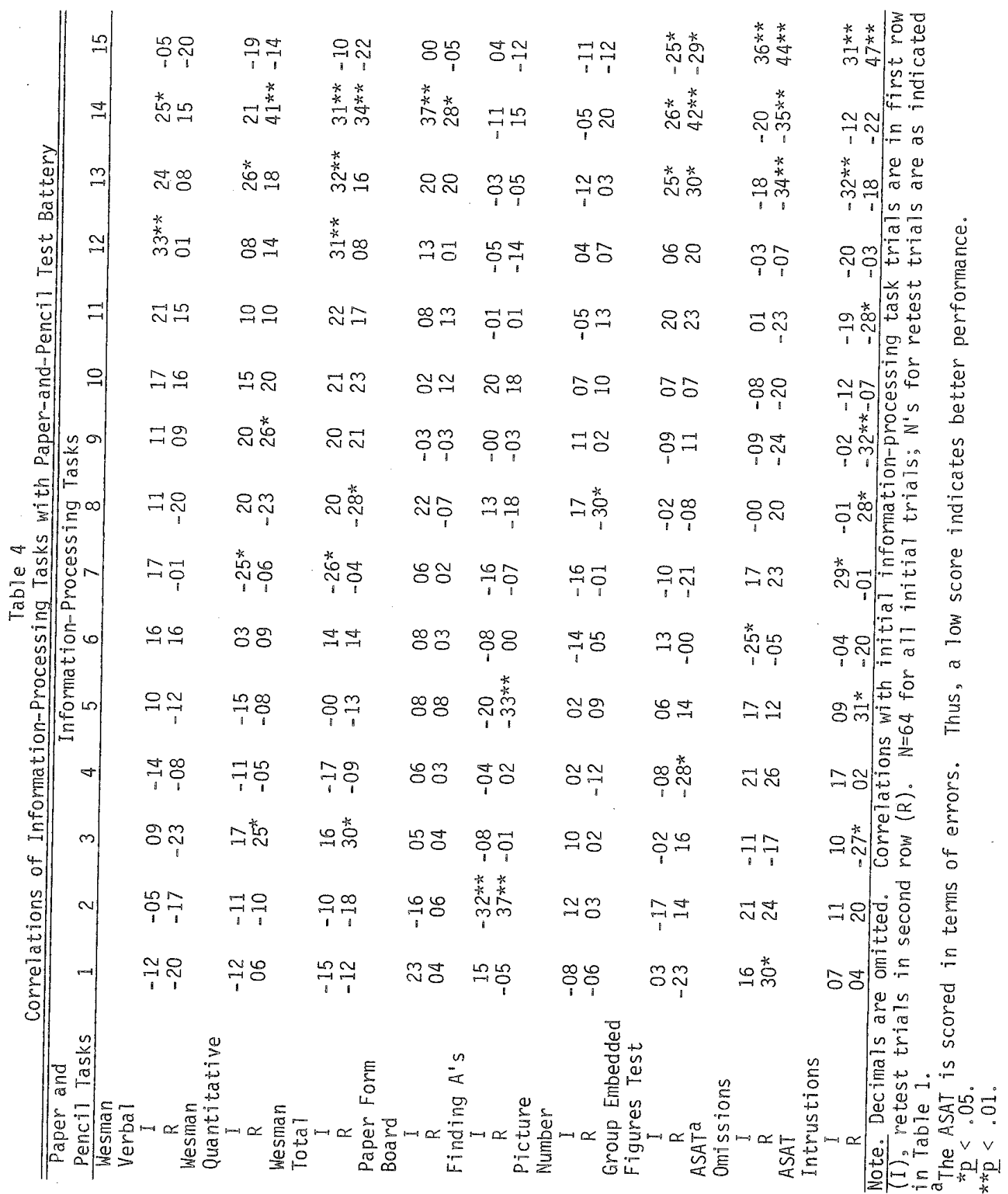

Downloaded from the Digital Conservancy at the University of Minnesota, http://purl.umn.edu/93227. May be reproduced with no cost by students and faculty for academic use. Non-academic reproduction requires payment of royalties through the Copyright Clearance Center, http://www.copyright.com/ 
Table 5

Means, Standard Deviations and Correlations for Computerized Preferences ${ }^{2}$

\begin{tabular}{lcccccc}
\hline Computerized & \multicolumn{7}{c}{ Correlations } & & \\
Preferences & 1 & 2 & 3 & Mean & SD & Range \\
\hline Stimulus Pace & $65^{* *}$ & -13 & -18 & .61 & .19 & $.23-1.0$ \\
Stimulus Variety & & $39 * *$ & $62^{* *}$ & 4.91 & .96 & $1.0-6.0$ \\
Response Variety & & & $62^{* *}$ & 4.95 & .98 & $1.0-6.0$ \\
\hline
\end{tabular}

Note. Decimal points are omitted from correlation coefficients. Reliability data, test-retest, are located along the diagonal.

$a_{N}=64$.

$* x p<.01$.

lations between Stimulus Pace and the variety measures did not reach statistical significance.

The Work Itself/Work Environment Preference Questionnaire (WI/WEP) is a paper-andpencil test of job or task preferences. Correlations between the WI/WEP scales and the initial computerized preference trials are presented in Table 6. None of the WI/WEP scales correlated significantly with Stimulus Pace. This finding was not surprising in that mone of the WI/WEP scales measured a variable similar in interpretation to Stimulus Pace. The WI/WEP variety scale was significantly correlated with Stimulus Variety, and the WI/WEP job difficulty and job complexity scales were significantly correlated with Response Variety.
Correlations between computerized preferences and the paper-and-pencil test battery were computed. Only one of the correlations, with omissions on the ASAT, was significant $(r=-.28, p<.05)$. Thus, computerized preferences were generally independent of ability as measured by traditional tests.

The correlations between the initial and retest trials for information-processing tasks and the initial trials for the computerized preference measures are presented in Table 7. Inspection of Table 7 reveals that for the initial informationprocessing trials, several of the measures were significantly related to computerized preferences. Stimulus Pace was significantly correlated with Simultaneous Memory Intercept, Vis-

Table 6

Correlations of WI/WEP with Computerized Preferences ${ }^{\text {a }}$

\begin{tabular}{|c|c|c|c|}
\hline WI/WEP Scales & $\begin{array}{l}\text { Compute } \\
\text { Stimulus } \\
\text { Pace }\end{array}$ & $\begin{array}{l}\text { Preferen } \\
\text { Stimulus } \\
\text { Variety }\end{array}$ & $\begin{array}{l}\text { Response } \\
\text { Variety }\end{array}$ \\
\hline $\begin{array}{l}\text { Variety } \\
\text { Attention } \\
\text { Job difficulty } \\
\text { Job complexity } \\
\text { Decision making } \\
\text { Job person fit }\end{array}$ & $\begin{array}{l}06 \\
-00 \\
-02 \\
-13 \\
-15 \\
-05\end{array}$ & $\begin{array}{l}26^{*} \\
-08 \\
12 \\
20 \\
13 \\
04\end{array}$ & $\begin{array}{l}22 \\
-02 \\
33 * \\
27 * \\
16 \\
-05\end{array}$ \\
\hline
\end{tabular}

Note. Decimal points are omitted.

$\overline{a N}=64$.

$*_{\mathrm{p}}<.05$ 
wal Search Intercept, and Choice RT. Thus, the faster the reaction time, the faster the expressed preference for pace. Vector Memory was significantly correlated with Stimulus Variety, and both Linear and Matrix Scanning were significantly correlated with Response Variety. Thus, scanning ability, memory for stimuli, and the ability to manipulate objects in space were associated with the preference for greater task variety. However, these results were not supported by the correlations between initial computerized preference data and the retest trials of the information-processing tasks. The only consistent result when moving from initial to retest trials for the information-processing tasks was for Response Variety and Matrix Scanning. With the exception of Response Variety and Array Memory, there were no other significant correlations between initial preference trials and information-processing retest trials.

\section{Discuss:ion}

The primary purpose of this study was the development and psychometric investigation of a computerized information-processing-based test battery. A battery of tests was developed that could be computer scored and administered to groups of people in a reasonable amount of time. For most measures, internal-consistency reliabilities exceeded 8 and there was evidence

Table 7

Correlations of the Information-Processing

Tasks with Computerized Preferences ${ }^{2}$

\begin{tabular}{|c|c|c|c|c|c|c|}
\hline \multirow[b]{3}{*}{ Tasks } & \multicolumn{5}{|c|}{ Computerized Preferences } & \multirow{3}{*}{$\frac{\text { Variety }}{R}$} \\
\hline & $\overline{\text { Stimu }}$ & Tus Pace & StimuTus & Variety & Response & \\
\hline & $I$ & $R$ & $I$ & $R$ & I & \\
\hline 1 & 23 & -02 & 09 & 06 & 03 & -18 \\
\hline 2 & 10 & -02 & -16 & -03 & -07 & 18 \\
\hline 3 & 10 & -05 & 00 & 08 & 24 & 23 \\
\hline 4 & $23^{*}$ & 12 & 01 & 07 & -04 & -17 \\
\hline 5 & -08 & -06 & 01 & -02 & 10 & 22 \\
\hline 6 & 09 & 09 & 10 & -01 & 19 & 06 \\
\hline 7 & $29 \%$ & 05 & 03 & 11 & 09 & -04 \\
\hline 8 & -02 & 20 & 08 & .03 & 12 & 12 \\
\hline 9 & 21 & -75 & -04 & -06 & 18 & 03 \\
\hline 10 & -23 & -20 & 05 & 05 & 05 & 11 \\
\hline 11 & 00 & 02 & 09 & -12 & $34 * *$ & 13 \\
\hline 12 & 02 & -20 & 07 & 05 & $30 *$ & $38 * x$ \\
\hline 13 & -07 & 02 & -06 & 03 & 13 & $38^{*}$ \\
\hline 14 & -03 & 00 & $25^{*}$ & 22 & 23 & -01 \\
\hline 15 & $25 \%$ & 00 & -08 & -08 & 02 & 13 \\
\hline
\end{tabular}

Note. Decimals are omitted. Correlations of initial preference measures with initial information-processing trials appear in first column (I), correlations of initial preference measures with information-processing retest trials appear in the second column $(R)$. For initial trials $N=64$, for retest see Table 1 . $* \mathrm{p}<.05$. $* x p<.07$. 
of convergent and discriminant validity for the measures.

Two exceptions to the generally promising findings were the test-retest reliabilities for all the measures and the internal-consistency reliabilities of the slope measures. The low internal consistency of the slope measures was probably due to the small number of points, 6 or less per letter, used in estimating the slope. The low testretest reliabilities may have been due to changes in processing strategies. Chiang and Atkinson (1976) also found a low test-retest correlation for the slope measures $(r=.28)$ for Day 1 to Day 2 , which they interpreted as due to a practice effect. Although Chiang and Atkinson (1976) did obtain high test-retest reliabilities for the tasks other than slope, as previously mentioned, their study was designed to maximize reliability and their subjects were drawn from a sample of superior intelligence. It appears that in a more normal sample, performance may require longer periods to stabilize.

As Hunt (1978) has pointed out, the use of the linear function procedure to define slope and intercept makes no assumption about the nature of the underlying process. However, in predicting psychometric scores from the memory-scanning tasks, two assumptions that must be made are (1) that prion learning is not necessary and practice effects are stable; and (2) that subjects do not differ in their processing strategies. Thus, the assumption that all subjects use a sequential exhaustive strategy is not necessary as long as all subjects use simillar strategies (Taylor, 1976). However, the low test-retest reliabilities and the presence of negative slopes for the Visual Search Task suggest that the assumption of similar strategies was violated.

The present study did find evidence of convergent validity for the intercept measures and several of the accuracy measures. Of particular interest was the significant correlations between the intercept measures for the scanning tasks after controlling for Choice RT. This suggests that there was sorne component of the intercept not accounted for by Choice $\mathbb{R T}$, on which there was individual differences. Thus, a component may be missing from the traditional explanation of intercept as involving encoding, binary decision, and response production.

In addition, the information-processing memory scanning tasks did not correlate highly or consistently with the traditional paper-and-pencill tests, the Auditory Selective Attention Test or the Group Embedded Figures Test. The basis for hypothesizing that there should be a correlation between macro paper-and-pencil tests and the information-processing-based measures was Hunt's cycle time concept (Hunt et al., 1973). According to this concept, all information-processing times should be positively intercorrelated and negatively correlated with intelligence tests. However, the present study, along with $\mathbf{S}$. Sternberg's review (1975) and Lumneborg's results (1977), have failed to support the cycle time concept.

An alternative possibility is that informationprocessing times vary within and across persons (Carroll, 1976; Stemberg, R., 1979). Thus, individual differences in time to retrieve information from long-term memory store may differ from individual differences in time to retrieve information from short-term memory store. Under this model, the information-processing components of a task would first have to be determined and then relevant information-processing measures summed, assuming a simple additive model, to predict performance.

An alternative to attempts to measure micro. cognitive processes, such as memory scamning, is the computerized measurement of more macro abilicies. For example, the test in the Graphic and Interactive Processing (GRIP) battery (Cory, 1977; Cory et al., 1977) contain items very similar to items found in paper-and-pencil tests, and many of the items could be presented in paperand-pencil format, with the exceptions of recording response latency and controlling stimu lus presentation time. This type of task has the advantages of greater element correspondence between computerized tasks and the paper-andpencill tasks. In the present study, response ac- 
curacy measures did correlate significantly with several of the paper-and-pencil tests. However, these correlations were not surprising in that the response accuracy measures and the paper-andpencil tests were intended to measure very similar concepts. Thus, this approach involves the adaptation of paper-and-pencil tests to the computer rather than the attempt to explain constructs underlying paper-and-pencil test performance by the measurement of underlying cognitive processes.

The second purpose of this study was the development of computerized preference measures. These measures were independent of traditional ability tests but did correlate with the computerized information-processing measures, with greater information-processing ability being associated with a greater preference for task pace and variety. Thus, there does appear to be conceptual meaning to individual preferences in information processing. However, these measures took a long time to administer, compared to traditional paper-and-pencil tests; and the distribution of scores and test-retest reliabilities were not encouraging for Stimulus Variety and Response Variety. The results for Stimulus Pace were more positive. One explanation for the discrepancies is that Simulus Pace was more concrete, dealing with actual speeds, while the variety measures were more abstract. In addition, the correlation between Stimulus Variety and Response Variety was as high as the test-retest reliabilities. Although earlier pilot studies suggested that task variety was logically and empirically composed of two components-response and stimulus variety - in the present study subjects did not appear to distinguish the two concepts.

In an earlier study, Panek et al. (1979) demonstrated that older adults preferred a significantly slower pace for working at a task and that preference for Stimulus Pace correlated significantly with motor $R T$, selective attention, and field independence. Panek et al. (1979) concluded that if older workers were allowed to work at their preferred pace, they could work as effectively as younger workers. Avolio et al. (1979) confirmed Panek et al.'s (1979) resulis that individuals who were field dependent and were poor at maintaining attention in the presence of competing stimwli preferred a slower pace of stimulus presentation, although the relationship was moderately low. Thus, the computerized Stimulus Pace does measure a significant individual task preference that correlates with important information-processing abilities.

In summary, the present study demonstrated the feasibility of developing a computerized information-processing test battery based on $\mathbb{S}$. Sterwberg's $(1966,1969,1975)$ memory-scanning paradigm as well as the potential for the development of computerized information preference measures. However, correlations between the information-processing tasks and traditional paper-and-pencil measures generally were nonsignificant or low, consistent with the .3 ceiling for correlations between short-term memory measures and intelligence tests (Sternberg, R., 1981). A number of recent reviews (Hunt, 1980; Sternberg, R., 1981) and the present study suggest that further studies correlating simple information-processing tasks and global intelligence tests would be of little value. A more positive line of research would be to follow $\mathbb{R}$. Sternberg's (1981) recent suggestion for studies relating information-processing tasks to real-world behavior. Using information-processing measures of short-term memory to predict task performance should result in higher correlations when used to predict performance on real-world tasks which place heavy demands on short-term memory. Rather than simply borrowing experimental measures and correlating these with traditional tests, studies should attempt to describe the information-processing demands of realworld tasks and then develop measures of these demands.

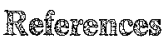

Avolio, B. J., Alexander, R. A., Barrett, G. V., \& Sterns, H. L. Analyzing preference for pace as a 
component of task performance. Perceptual and Motor Skills, 1979, 49, 667-674.

Avolio, B. Jo, Alexander, R. A., Barrett, G. V., \& Sterns, H. L. Designing a measure of visual selective attention to assess individual differences in information processing. Applied Psychological Mea. surement, 1981, 3, 27-42.

Barret, G. V. Task design, individual attributes, work satisfaction and productivity. In A. R. Negandhi \& B. Wilpert (Eds.), Work organization research: European and American perspectives. Kent OH: Kent State University Press, 1978.

Barrett, G.V., Dambrot, F. H., \& Smith, G. R. The relationship between individual attributes and job design: Review and annotated bibliography. ISAS Caralog of Selected Documents in Psychology, 1977, 7, 118 (Ms. No. 1608).

Blood, M. R., \& Hulin, C. L. Alienation, environmental characteristics, and worker response. Journal of Applied Psychology, 1967, 51, 284-290.

Carroll, J. B. Psychometric tests as cognitive tasks: A new "Structure of Intellect." In $\mathbf{L}$. Resnick (Ed.), The nature of intelligence. Hillsdale NJ: Erlbaum, 1976.

Cascio, W. F. Value orientation, organizational tewards, and job satisfaction. Unpublished doctoral dissertation, Department of Psychology, University of Rochester, 1973.

Chiang, A., \& Atkinson, R. Individual differences and interrelationships among a select set of cognitive skills. Memory and Cognition, 1976, 4 , $661-672$.

Cory, C. H. Relative utility of computerized versus paper-and-pencil tests for predicting job perform. ance. Applied Psychological Measurement, 1977 , $1,551-564$.

Cory, C. H., Rimland, B., \& Bryson, R. H. Using computerized tests to measure new dimensions of abilities: An exploratory study. Applied Psychological Measurement, 1977, 1, $101-110$.

Ekstrom, R. B., French, J.W., Harman, H.H., \& Dermen, D. Manual for kit of factor referenced cognitive tests. Princeton NJ: Educational Testing Service, 1976.

French, J. R. P., Jro, \& $\mathbb{K}$ ahn, R. L. A programmatic approach to studying the industrial environment and mental health. Joumal of Social Issues, 1962 , $18,1-47$.

Gopher, D. G., \& Kahneman, D. Individual differences in attention and the prediction of flight criteria. Perceptual and Motor Skills, 1971, 33, $1335-1342$.

Hackman, J.R o \& Lawler, E. E. Employee reactions to job characteristics. Ioumal of Applied Psychology, 1971, 55, 759-786.
Hackman, J.R., \& Oldham, G. R. Development of the Job Diagnostic Survey. Journal of Applied $\mathbb{P}$ sychology, 1975, 60, 159-170.

Hunt, E. Mechanisms of verbal ability. Psychological $_{\text {S }}$ Review, 1978, 85, 109-130.

Hunt, $\mathbb{E}$. Intelligence as an information-processing concept. British Journal of Psychology, 1980, 71, $449-474$.

Hunt, E., Frost, No, \& Lunneborg, C. Individual differences in cognition: A new approach to intelligence. In $G$. H. Bower, Advances in learning and motivation (Vol. 7). New York: Academic Press, 1973.

Hunt, E., Lunneborg, C., \& Lewis, J. What does it mean to be highly verbal? Cognitive Psychology, $1975,7,194-227$.

Knapp, P.R. The Maudsley personality invertory. San Diego CA: Educational and Industrial Testing Service, 1962.

Lord, F.M. Applications of item response theory to practical testing problems. Hillsdale $\mathbb{N}$ : Erlbaum, 1980.

Likert, R., \& Quasha, W. H. Manual: Revised Minnesota Paper Form Broard. New York: Psychological Corporation, 1970.

Lunneborg, C. E. Choice reaction time: What role in abihity measurement? Applied PSychological Measurement, 1977, 1, 309-330.

Lunneborg, C. E. Some information-processing correlates of measures of intelligence. Maltivariate Behavioral Research, 1978, 13, 153-161.

Mihal, W. L., \& Barrett, G. V. Individual differences in perceptual information-processing and their relation to automobile accident involvement. Journal of Applied Psychology, 1976,61, 229-233.

Neisser, U. Cognitive psychology. New York: Appleton, 1967.

Newell, A.s \& Simon, H. Human problem solving. Englewood Cliffs NI: Prentice-Hall, 1972.

Panek, P. E., Barrett, G.V., Alemander, R. A.s \& Sterns, H. L. Age and self-selected performance pace on a visual monitoring inspection task. Aging and Work, 1979, 2, 183-191.

Snow, R. E. Theory and method for research on aptitude processes. In R. I. Sternberg \& D. K. Detter man (Eds.), Human intelligence. Norwood NI: Ablex, 1979.

Sternberg, $\mathbb{R}$. Intelligence, information processing and analogical reasoning: The componential analysis of human abilities. Hillsdale NJ: Erlbalum, 1977.

Sternberg, $\mathbb{R}$. The nature of mental abilities. American Psychologist. 1979, 34, 214-230.

Sternberg, R. Nothing fails like success: The search for an intelligent paradigm for studying intelli- 
gence. Journal of Educational Psychology, 1981 , $73,142-155$.

Sternberg, S. High-speed scanning in human mem. ory. Science, $1966,153,652-654$.

Sternberg, S. Memory scanning: Mental processes revealed by reaction-time experiments. American Scientist, $1969,57,421-457$.

Sternberg, \$. Memory scanning: New findings and current controversies. Quaterty Joumal of Experimental Psychology, 1975,27, 1-32.

Taylor, D. A. Stage analysis of reaction time. Psychological Bulletin, 1976,83, 161-191.

Tumer, A. W., \& Lawrence, P. R. Industrial jobs and the worker: An investigation of response to task attributes. Boston: Harvard University, Graduate School of Business Administration, 1965.

Wesman, A. G. Wesman personnel classification test manual. New York: Psychological Corporation, 1965.

Whitely, S. E. Information-processing of intelligence test items: Some response components. Applied Psychological Measurement, 1977, 1, 465-476.

Witkin, H. A., Oltman, P. K., Raskin, E., \& Karp, S. A. Manual: Group embedded figures test. Palo Alto CA: Consulting Psychological Press, 1971.
Witkin, H. A., Lewis, H. B., Machover, K., Meissner, P. M., \& Wagner, S. Personality through perception. New York: Haynes, 1954.

Wood, R. Response-contingent testing. Review of $\mathbb{E} d-$ ucational Research, 1974, 48, 529-544.

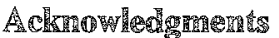

This research was supported by the Office of Naval Research, Contract N00014-75-C-0985, NR 151-377, Gerald V. Barrett, Principal Investigator. Any additional tables desired can be obtained from the first author.

\section{A}

Send requests for reprints or further information to Gerald V. Barrett, Psychology Department, The University of Akron, Akron OH 44325. 